\title{
REFORMULAR O FPE PARA ADEQUAR O FEDERALISMO FISCAL
}

Coluna publicada em 23.10.2012: <http://www.conjur.com.br/2012-out-23/ contas-vista-reformular-fpe-adequar-federalismo-fiscal $>$

Reproduzindo o que já disse na coluna do dia 28 de agosto de 2012 (Transferências voluntárias geram desequilibrio federativo), inicio esta lembrando que estamos em uma Federação que tem entre seus pilares o respeito à autonomia financeira dos entes que a compõem.

Ao discorrer sobre a dificuldade que é construir um Estado Federal, especialmente no que tange ao exato desenho das partilhas de encargos e atribuições, de modo a compatibilizar as receitas com as despesas, chamei a atenção para a questão das transferências voluntárias, instrumento de extrema relevância para obter este desejado equilíbrio.

Desta feita, pelas razões que vão ser expostas em seguida, o foco é outro: as transferências obrigatórias, mais especificamente a transferência constitucional do FPE (Fundo de Participação dos Estados e Distrito Federal).

Não é fácil, em nenhum Estado, e menos ainda naqueles que se organizam na forma federativa, dividir as receitas públicas. Vários são os métodos e instrumentos pelos quais essa partilha se operacionaliza nos Estados Federados.

No Brasil, com seu federalismo cooperativo, temos, inicialmente, uma repartição das fontes de receitas permitindo a cada ente federado dispor de competências arrecadatórias próprias, obtendo recursos tanto por vias tributárias quanto não tributárias, sendo as primeiras usualmente mais relevantes, responsáveis pela maior parte da arrecadação.

As características de cada tributo, em função de diversos fatores, dificultam a atribuição precisa de cada espécie aos diversos entes federados; e o comportamento da arrecadação é também diverso para cada ente, tornando inadequada 
uma partilha de recursos entre os entes federados promovida somente pela distribuição de competências arrecadatórias.

Em função disso, torna-se de extrema relevância o mecanismo de repartição do produto da arrecadação, por meio do qual um ente federado detém a competência para instituição e cobrança do tributo, mas deve dividir o produto arrecadado com outros entes federados.

Por meio da repartição do produto da arrecadação, muitas ineficiências são eliminadas, e abre-se a oportunidade de se introduzirem critérios de redistribuição de recursos que podem ser úteis para aperfeiçoar o sistema de partilha e eliminar desigualdades e desequilíbrios diversos, garantindo a autonomia financeira dos entes federados, com mais equidade e eficiência, corrigindo-se os desequilíbrios verticais e horizontais existentes na Federação.

Os mais importantes instrumentos desse federalismo fiscal cooperativo no Brasil, atualmente, são o Fundo de Participação dos Estados e do Distrito Federal (FPE) e o Fundo de Participação dos Municípios (FPM).

Embora existam registros de previsões constitucionais de partilhas de receitas tributárias na Constituição de 1937 (art. 20) e de 1946 (art. 15), os Fundos de Participação ora referidos, na forma atual, surgiram com a Emenda Constitucional 18, de $1965 .{ }^{1}$

A Constituição vigente os prevê no artigo 159, I, $a$ e $b$, destinando-lhes parcela do produto da arrecadação dos impostos sobre a renda e proventos de qualquer natureza (IR) e sobre produtos industrializados (IPI).

O artigo 161, II, da Constituição estabelece que "cabe à lei complementar estabelecer normas sobre a entrega dos recursos de que trata o art. 159, especialmente sobre os critérios de rateio dos fundos previstos em seu inciso I, objetivando promover o equilíbrio socioeconômico entre Estados e entre Municípios". A Lei Complementar 62, de 28 de dezembro de 1989, definiu os critérios de partilha.

O Fundo de Participação dos Estados e Distrito Federal é composto por $21,5 \%$ da arrecadação da União com o imposto sobre a renda (IR) e com o imposto sobre produtos industrializados (IPI) (CF, art. 159, I, a), e seus recursos são distribuídos aos estados e Distrito Federal mediante fórmula que leva em consideração a região da federação da qual o estado faz parte, a superfície territorial, a renda per capita e a população.

1 Pode-se ver a evolução histórica mais detalhada em texto anterior de minha autoria: CONTI, José Mauricio. Federalismo fiscal e fundos de participação. São Paulo: Juarez de Oliveira, 2001, p. 61-68. 
O Fundo de Participação dos Municípios é composto por 22,5\% da arrecadação da União com o imposto sobre a renda (IR) e com o imposto sobre produtos industrializados (IPI) (CF, art. 159, I, b), e seus recursos são distribuídos aos municípios mediante fórmula que leva em consideração o fato de ser capital do Estado, a renda per capita e a população. Recentemente, por meio da Emenda Constitucional 55/2007, foi majorada a composição das receitas do Fundo, com a inclusão de $1 \%$ das receitas do IR e do IPI, a serem distribuídas aos municípios no primeiro decêndio do mês de dezembro de cada ano.

As transferências intergovernamentais oriundas desses Fundos têm natureza obrigatória, ou seja, não se vinculam a programas governamentais específicos cuja operacionalização fique sujeita à decisão de autoridade para se efetivar. São também transferências incondicionadas, ou seja, os recursos transferidos são de livre aplicação pelo ente federado que as recebe.

Passam a integrar as receitas correntes do ente federado que, em regra, as utiliza para financiar as despesas correntes, caracteristicamente pouco comprimíveis, com estreita margem para serem reduzidas.

Disso resultam alguns problemas interessantes e de difícil solução.

É o caso, por exemplo, das oscilações na arrecadação do IPI, imposto com relevante função extrafiscal, utilizado pela União no exercício de sua política fiscal e que, frequentemente, tem suas alíquotas alteradas, com consequente efeito no montante arrecadado e, por consequência, transferido sem que os estados e municípios possam ter qualquer controle ou ingerência. Evidente a dificuldade orçamentária causada aos entes subnacionais, que ficam à mercê das ações da União e também do comportamento do mercado, para receber recursos destinados a pagar salários de servidores, contratos em andamento etc.

Outra questão refere-se à adequação dos critérios de partilha desses recursos.

No caso do FPE, o primeiro critério (LC 62, art. $2^{\circ}$ ) é regional, destinando-se, das receitas do Fundo, 85\% para as unidades da Federação integrantes das regiões Norte, Nordeste e Centro-Oeste; e $15 \%$ para as unidades da Federação do Sul e do Sudeste, com os coeficientes individuais, para cada estado, sendo definidos na forma do anexo único da lei, para vigorar provisoriamente até o exercício de 1991, a serem alterados posteriormente com base no censo do IBGE.

Ocorre que a alteração dos critérios, como se pode imaginar, provoca modificações significativas na arrecadação dos estados beneficiários, em receitas cuja redução causa sério transtorno nas respectivas finanças, pelas razões já expostas. ${ }^{2}$ Por

2 Só para que se tenha uma ideia, em alguns Estados, as transferências do FPE chegam a representar quase $50 \%$ das receitas correntes. 
consequência, previsível a dificuldade política em aprovar lei com novas disposições. Tão difícil que nunca chegou a ser $\operatorname{aprovada}^{3}$ e, até hoje, passados mais de vinte anos, continuam vigentes os mesmos critérios.

Em razão disso, estados que se consideraram prejudicados moveram ações diretas de inconstitucionalidade, por ação e omissão, em face da prorrogação sucessiva da vigência dos artigos que fixam os critérios de rateio e não estabelecimento de novos, nos termos determinados pela Constituição, que resultaram em quatro ações (ADIs 875, 1.987, 2.727 e 3.243), julgadas em conjunto por decisão de 24 de fevereiro de 2010 (Tribunal Pleno, rel. Min. Gilmar Mendes).

O Supremo Tribunal Federal reconheceu ser incompatível com o texto constitucional que determinou sejam os critérios fixados com o objetivo de promover o equilíbrio socioeconômico, a manutenção de regra estabelecida provisoriamente há mais de 20 anos.

Em decisão interessante e inovadora, julgou procedentes os pedidos, declarando inconstitucionais o artigo $2^{\circ}$, I e II, $\$ \$ 1^{\circ}, 2^{\circ}$ e $3^{\circ}$, e o anexo único, da Lei Complementar 62, de 1989, que fixam os critérios hoje vigentes de partilha das receitas do FPE. No entanto, sendo inconstitucionais os referidos dispositivos, inviável se torna a operacionalização da distribuição dos recursos, o que evidentemente provocaria um caos nas finanças dos Estados, razão pela qual foi declarada a inconstitucionalidade "sem pronúncia de nulidade", assegurando-se a aplicação dos referidos dispositivos até 31 de dezembro de 2012.

Compreenderá agora o leitor a razão desta coluna.

O dia 31 de dezembro de 2012 está aí. Daqui a dois meses encerra-se a sessão legislativa e, portanto, o prazo para a supressão dessa futura lacuna legislativa, com a aprovação da lei que venha a regulamentar os novos critérios de rateio do Fundo de Participação dos Estados e Distrito Federal, de fundamental importância para as finanças públicas.

Sendo inviável nova prorrogação, até porque os critérios hoje vigentes foram declarados inconstitucionais justamente por serem decorrentes de prorrogaçóes de normas anteriores, estamos diante de uma decisão definitiva de nossa Suprema Corte estabelecendo esse prazo fatal para a vigência da norma que terá de ser cumprido.

Faltando dois meses para o final do prazo - que não se pode dizer tenha sido pequeno, uma vez que a decisão é de fevereiro de 2010 - e estando nosso Congresso às voltas com outras preocupações, tais como as eleições municipais em andamento,

A lei veio na ser aprovada em 17 de julho de 2013 (Lei Complementar 143). 
acompanhamento do julgamento do mensalão e a sempre presente e importante votação da lei orçamentária, sérias razões há para se temer de que o prazo não venha a ser respeitado.

As reformulações das partilhas dos recursos do FPE, bem como do FPM, são decisões da mais alta relevância para a adequação do federalismo fiscal brasileiro, politicamente difícil de obter consenso e, por isso, deveriam ser objeto de intensos debates que permitissem avaliar as múltiplas possibilidades de utilização de novos critérios, mais justos, eficientes e coerentes com os objetivos fundamentais da nossa República Federativa.

Nesse aspecto, o prejuízo é enorme e já está consumado, pois até agora pouco se fez e não há mais como recuperar o tempo perdido. Só nos resta esperar e que, no próximo dia 31 de dezembro, a surpresa não seja por demais desagradável... 
